Paideusis

\title{
Toward a Pedagogy of Dialogical Resistance
}

\section{Rob Foster}

Volume 16, Number 2, 2007

URI: https://id.erudit.org/iderudit/1072577ar

DOI: https://doi.org/10.7202/1072577ar

See table of contents

Publisher(s)

Canadian Philosophy of Education Society

ISSN

0838-4517 (print)

1916-0348 (digital)

Explore this journal

Cite this article

Foster, C. (2007). Toward a Pedagogy of Dialogical Resistance. Paideusis, 16(2), 15-33. https://doi.org/10.7202/1072577ar

\section{Article abstract}

Martin Buber provides an ethical understanding of dialogical resistance. But does this notion take sufficiently into account the oppositional force of resistance and the shifting realities of monologic relations? How are we to understand the terms dialogue and resistance? What impact will the ethics of dialogical resistance have on evaluation practices in public education? To address these questions, each term of this dyadic relationship must be defined. First I will differentiate dialogue from conversation, argument and discussion. Secondly it must be shown that my view of ethical resistance cannot be synonymous with criticism, disagreement or dissent per se, though undoubtedly certain connections do exist in practice. Then it will be appropriate to delve into a linguistic analysis of the substantive terms of dialogue and resistance as separate notions before using them together as intersecting concepts. Once I have delineated dialogical resistance as a dyadic tension, I will highlight Martin Buber's passion for human worth - the motivation for respect- as the necessary condition for the ethical success of dialogical resistance. The balance of this paper will take a look at the psychological roots of dialogical resistance, the complexity of practising dialogical resistance, and asymmetrical relations in the classroom.
This document is protected by copyright law. Use of the services of Erudit (including reproduction) is subject to its terms and conditions, which can be viewed online.

https://apropos.erudit.org/en/users/policy-on-use/ 


\title{
Toward a Pedagogy of Dialogical Resistance
}

\author{
C. ROB FOSTER \\ OISE of the University of Toronto, Canada
}

\begin{abstract}
Martin Buber provides an ethical understanding of dialogical resistance. But does this notion take sufficiently into account the oppositional force of resistance and the shifting realities of monologic relations? How are we to understand the terms dialogue and resistance? What impact will the ethics of dialogical resistance have on evaluation practices in public education? To address these questions, each term of this dyadic relationship must be defined. First I will differentiate dialogue from conversation, argument and discussion. Secondly it must be shown that my view of ethical resistance cannot be synonymous with criticism, disagreement or dissent per se, though undoubtedly certain connections do exist in practice. Then it will be appropriate to delve into a linguistic analysis of the substantive terms of dialogue and resistance as separate notions before using them together as intersecting concepts. Once I have delineated dialogical resistance as a dyadic tension, I will highlight Martin Buber's passion for human worth - the motivation for respect- as the necessary condition for the ethical success of dialogical resistance. The balance of this paper will take a look at the psychological roots of dialogical resistance, the complexity of practising dialogical resistance, and asymmetrical relations in the classroom.
\end{abstract}

Logically, the Other is the correlate of the Self as Agent. It is that which resists, and in resisting supports, my intention. ${ }^{1}$

What is dialogical resistance? Does it take sufficiently into account the oppositional force of resistance and the complex and shifting realities of power relations? To satisfy these questions, I will begin by defining my terms. First, I will differentiate dialogue from conversation, argument, and discussion. Secondly, it must be shown that my view of ethical resistance cannot be synonymous with criticism, disagreement or dissent per se, though there are certain connections in practice. Then it will be appropriate to delve into a linguistic analysis of the substantive terms of dialogue and resistance as separate notions before using them together as intersecting concepts. Once defined as a dyadic tension, it will be useful to highlight their combined merits by arguing briefly against the inadequacies of certain traditional philosophies of education and for their compatibility with some current authors. I will use Martin Buber's passion for human worth -the motivation for respect -as the necessary condition for the ethical success of dialogical resistance. ${ }^{2}$

The balance of this paper will take a look at the psychological roots of dialogical resistance, the complexity of practising dialogical resistance, and asymmetrical relations in the classroom.

\footnotetext{
${ }^{1}$ John Macmurray, Persons in Relation, 79

${ }^{2}$ His is not a unique claim, but the outworking of this condition in terms of dialogical relations and confrontation provides fertile soil for productive, ethical conflict.

(C) Copyright 2007. The author, C. Rob Foster, assigns to Paideusis the right of first publication and educational and non-profit institutions a non-exclusive license to use this document for personal use and in courses of instruction provided that the article is used in full and this copyright statement is reproduced. Any other usage is probibited without the express permission of the author.
} 


\section{Ethical Dialogue}

Ethical dialogue in the way I intend to justify and practise it must not be confused with conversation. Participants in conversation engage in informal talk that may appear to cross barriers of culture, race, and religion. A dominant-view teacher ${ }^{3}$ may talk about the weekend with a student of a marginal perspective and simply overlook differences. This may be a form of polite avoidance. Burbules states that dialogue remains unauthentic as long as it moves through "acceptable channels" of communication. ${ }^{4}$ Talking about the weekend may assume a dominant position of leisure time, spending money, entertainment and travel that only those of a certain class and lifestyle enjoy talking about. A conversation blind to real differences in values and experience can be socially quite acceptable, but it does not constitute meaningful dialogue. Conversation may go so far as to talk about differences, yet Burbules insists that dialogue requires persistence through differences ${ }^{5}$. This means conversation will usually end where differences begin to create tension and possible conflict.

This is not to say that light-hearted and non-contentious conversation has no place in healthy human relationships. But in terms of the ethical dimension of dialogue, it leaves out certain critical features. Ethical dialogue reaches beyond the niceties of conversation into the psyche. Whether from a stance of silent attentiveness or of positioning oneself against the other, dialogue must begin on the basis of both commonality and difference. It draws out the deep structure of relating by addressing inequities due to power, position, wealth, language, or culture. From a dominant perspective there is the straining to see through the eyes and feel through the affective responses of the marginal perspective. Conversely, a person of marginal status takes a stand against dominance through dialogue that may deviate from "acceptable channels." From the standpoint of the dominant representative, unexpected anger, criticism or body language may challenge the status quo of conversation. The voice of dominance may then choose to avoid the deeper issues, or may have an ethical concern that thrusts the exchange into a deeper, more values-based zone of communication. ${ }^{6}$

A second distinctive of ethical dialogue comes to light when taken as dialogue for acceptance of others instead of dialogue for understanding others. Dialogue does not always lead to understanding another's position. Yet it ought to produce a deeper acceptance of the person whose position we fail to understand. How so? Burbules ties dialogue to drawing out unconscious, unspoken beliefs. ${ }^{7}$ I place these at the level of conscience. When conscience begins to speak through the process of dialogue, real and often irreconcilable differences sometimes come to light, underscoring the inherent philosophical, religious or values differences that cannot be bridged discursively. We may come to terms with the fundamental differences we simply cannot understand, in the sense of being able to follow logically from our own presuppositions. Yet at the same time the mutual disclosure of beliefs anchored within can bolster a new respect for one another as persons of worth who each have deeply held beliefs that fuel each one's thinking and passions.

\footnotetext{
${ }^{3}$ A dominant view in an upwardly mobile community may include references to movies, restaurants and other forms of entertainment tied to a middle class consumer lifestyle. A marginal view may not experience such experiences as normal, due to economic poverty or religious convictions.

${ }^{4}$ See Trifonas, Revolutionary Pedagogies, 251-252

${ }^{5}$ Burbules. Dialogue in Teacbing, 19

${ }^{6}$ A student of mine had a short and pleasant conversation with me as she entered the classroom. When she produced her assignment, I saw and pointed out that she had not followed the criteria. I returned it to her to try again, to which she replied flatly that she would not redo the work and take a "zero." The deeper question related to dialogue is then: "what was behind her refusal to comply? Was it sheer laziness, or more likely, was it a matter of feeling subjection to dominant standards taken as quashing personal expression? (The piece was a poem written by the student.) The conversation at the door needed to evolve into a dialogue of the heart in order to discover the ethical inequities this student was perhaps feeling at the time.
}

${ }^{7}$ Dialogue in Teaching, 19 
For example, if a student justifies stealing food from stores in New Orleans in the aftermath of hurricane Katrina, I struggle to understand this position as ethically viable -as a matter of principle. As I strain to see through his eyes, feel the poverty of blacks who live in New Orleans, I begin to see some justification for breaching property laws for the sake of survival. I nevertheless fail to understand it as my student does. In the end, as I hear his passion for blacks in that devastated city, I respect this student as a person with deeply held views, however divergent and incompatible with my own. Ethical dialogue can lead to an unexpected and uneasy connection between a lack of understanding and acceptance of the other as different.

If this is the case, agreement cannot be an expected outcome of dialogue. Burbules rightly ties this kind of expectation to a "false seduction" 8 that cajoles us into thinking agreement is the true test of successful dialogue. This is much too narrow a view. I concur with Burbules that more importantly it is "respect and concern that they share for one another, even in the face of disagreements" 9 that constitutes successful dialogue. ${ }^{10}$

To push the argument for dialogue in the absence of agreement further, one could say that such an expectation all too often plays into the hands of a dominant power. The process and parameters are preset, controlled entirely by one party over against the other. When I invite my students to come to a consensus on the topics, length and timing of summative evaluations, I have only opened up the arena of dialogue to discreet elements of evaluation I deem to be negotiable. I still represent and require the demands of the school system. For example, greater weight will still be placed on final performances rather than on qualitative accounts of progress in the form of shared assessments from both students and teacher. Dialogue for agreement on these terms amounts to a dialogue of complaisance. ${ }^{11}$ It leaves me as the teacher invulnerable to non- or anti-systemic approaches to evaluation. On the surface there is dialogue, but at the level of who is in control it is a monologue of complaisance. Burbules characterizes this as absorbing differences through subtle coercion to conform to dominant norms. ${ }^{12}$ In my view ethical dialogue allows for questioning of the dominant position, vulnerability and risk-taking on the part of the dominant representative, a willingness to de-center by stepping out of my systemic role and considering radical alternatives. In some cases perhaps a narrative of the student's reflective journey may be just as valid as a summative task performed in the classroom.

If not agreement, then should dialogue be taken as synonymous with argument? In one sense argument allows for underscoring different positions and points of view. This may counter in some measure the tacit control of "agreement." Better to have open claims to difference than hidden control in the guise of agreement. Yet when we ask what we mean by "argument" and its purpose, we begin to see cracks in the wall. Argument operates primarily as a cognitive process that highlights different points of view, each reasoning critically against the other and for its own position. As an offensive and defensive process of reasoning, it does not assume nor necessarily seek either agreement or understanding. Its aim is to demonstrate the rational weaknesses of the counter-arguments ${ }^{13}$. This is

\footnotetext{
${ }^{8}$ See Trifonis, Revolutionary Pedagogies, 256

${ }_{9}^{9}$ Dialogue in Teaching, 8

${ }_{10}$ Bridges makes a helpful distinction between an argumentative and reflective approach to discussion. The argumentative approach seeks resolution in the form of consensus, or a sufficient level of agreement for a shared decision. The reflective approach is more open-ended, embracing different points of view without expecting consensus. If a deeper mutual respect is gained through reflective interaction, this is time and effort well spent, in my view. See his Education, Democracy and Discussion, 38-40.

${ }^{11}$ I use the term "complaisance" in the sense of accommodating the other's wishes in an agreeable, obliging way, as used in French.

12 See Philosophy of Education, 1996, 122

13 Argumentative exclusion can be put in terms of refutation, which, according to Bridges, may be "threatening to anyone whose self-esteem or social authority is too closely associated in their own minds with their own capacity to be right. For such people, to expose themselves to refutation is to risk too much of what is essential to the maintenance of their own self-concept or of their public 'face'." Argument outside of the realm of a mutual
} 
the art of refutation used in different ways in philosophical arguments and formal debates. Argument for argument's sake may be a worthwhile exercise in sharpening one's power of reasoning, but it does not amount to ethical dialogue. Argument for the purpose of agreement may lead to nothing more than one side conceding to the powers of rational persuasion put forth by the other side. True dialogue takes the pressure off argumentation as a battle of wits, placing reason on the surface of a deeper attitude of openness, inclusion and receptivity to the other person. In this sense reasoning gives way to the quality and direction of the relationship. Differences of position, reasoning and beliefs are not denied, but fully taken into account within the basic attitude of openness to the other as one of equal worth.

A more inclusive approach to dialogue may be evident in discussion. Are dialogue and discussion synonymous? Bridges lays down the conditions for discussion: "mutual responsiveness of contributions" and "the readiness or disposition of the contributors to be affected by opinions one way or the other." 14 A discussion must remain open enough to keep participants from being "convinced of the unique wisdom of one's own opinion" and a willingness to accommodate one's point of view with the points of view of others. ${ }^{15}$ But does Bridges' idea of discussion promote anything more than a mutual openness and accommodation of "opinions"? How do I know the opinions of my fellow discussants are not contrived or mere posturing? Whose opinion will count as the most persuasive? Will it be the most passionate one, the most eloquent or the one who represents the dominant cultural view? Where does this leave the deeply convinced, though inarticulate, out-of-the-mainstream cultural participant? Bridges accounts for the reality of "prejudices and taken-for-granted assumptions" as contrary to productive discussion, but he does not address them directly through the process of discussion itself. He simply acknowledges that "subjective prejudices" present an obstacle. In my view, however, ethical dialogue by definition helps dredge up and deconstruct prejudices through the narrating self, ethical silence and encounters between discussants at the level of conscience. ${ }^{16}$ Bridges decontextualizes discussion, preferring to entertain the truth or falsity of "propositions" rather than to get at the source of these. Who speaks, how, and when, these are conditions deemed irrelevant. What counts are the "general rules of procedure....defining relevance and rationality." 17 He values intellectual honesty over understanding "personal relationships," including why and how we relate to each other as situational beings. In my view, dialogue cannot promote honesty without self-disclosure. We cannot separate intellectual honesty from an interface of consciences, and without a deep level of encounter of differences, we will never fully appreciate nor gain an accurate perception of the deeper level of commonality between us as fellow humans. By going deeper in mutual consciousness not just of ideas, opinions and propositions, but of differences of belief, background, language and culture, we can also go deeper in the mutual realization of our common identity as persons of worth. In fact, discussion as described by Bridges seems to exclude those who cannot articulate ideas and opinions in acceptable channels of rationality. How will a person who has not been schooled in the art of propositional language gain access to the discussion? Without more latitude for sharing personal narratives through the logic of story and in the context of each one's own experience and beliefs, however difficult to grasp propositionally, we may not be able in fact to find an authentic starting point for discussion. Through ethical dialogue, at least, when we cannot find a common language, we can still locate

sense of inestimable worth in this case alienates more than it produces resolution or understanding between differences. See Education, Democracy and Discussion, 44.

${ }^{14}$ Education, Democracy \& Discussion, 15

${ }^{15} \mathrm{Ibid}, 22$

${ }^{16}$ Narrative, silence and conscience are expanded upon in another paper "Three Pedagogical Levels of Dialogical Resistance."

${ }^{17}$ Education, Democracy \& Discussion, 88-89 
subrational life stories and suprarational beliefs that highlight our shared humanity. This may include silence, a look, a moment of spiritual connection. ${ }^{18}$

In summary, ethical dialogue cannot be reduced to a conversational exchange. It assumes difference and addresses inequities by challenging acceptable channels of communication. Although it may be informal in style, it persists in the pursuit of understanding differences rather than glossing them over. In understanding, dialogue draws out the unconscious level of beliefs, bringing to light these differences instead of vying for agreement. And when mutual understanding fails, the attempts at dialogue can persist through acceptance of the other as worthy of respectful confrontation. Ethical dialogue works against the rules of debate, argument, and refutation in demonstrating openness to dominant self-criticism in order to counter the subtle tendencies of dialoguing on the surface while hiding a subtext of monological control for compliance. Finally, it probes beneath the rationality of discussion. Discussion deals with opinions and rational positions while through dialogue we strive to reveal the source of these opinions and the narrative context for rational discourse.

\section{Ethical Resistance}

My view of resistance must now be tested against criticism, disagreement, or dissent. On the other hand, ethical resistance cannot be tied exclusively to non-rational, oppositional behaviours. It is neither merely talk nor merely action. It must combine both on a basis that undergirds both reason and action. I concur with Martinot that resistance is not so much "demanding" as it is "bringing a more humane world into existence." 19 Demands for change, provoked by rational analysis, debate, and argumentation, do not always arise out of a vision for a more "humane world". Giroux provides a counterbalancing view with his claim that "the concept of resistance (must) not be allowed to become a category indiscriminately hung over every expression of 'oppositional behaviour'." 20 Ethical resistance belongs neither exclusively to the side of reason nor the side of action. From what sort of wellspring does it then flow?

First, ethical resistance must follow the current of an integrally human pressure against dominance. ${ }^{21}$ It is at once cognitive, affective, and volitional in thrust. Ghandi's resistance to British Rule in India was steeped in rational discourse, a deep passion for universal justice, strong affective ties with the people of India, and a will that pushed his own body beyond its own limits (through hunger strikes). Martin Luther resisted Papal power and the political clout of a German prince with a unified position of reasonable arguments, an uncompromising will based on his beliefs, and a demonstrated attachment to the vernacular Bible common folks could understand. In this sense ethical resistance includes, but cannot be reduced, to rational criticism. ${ }^{22}$ For example, rational discourse used to criticize may be a skill that pertains to debating, a formal role, as used by a lawyer, for example; or that relates to a political role, like a union's bargaining team. It lacks in and of itself the essential link to an ethical stance that in my view requires a connection to affect, will, belief, and passion. This is not to say ethical resistance can only be authentic in the absence of critical judgments or justificatory arguments. But in

\footnotetext{
18 Some instances of significant connection cannot be manufactured by one's will or desire. They are gifts, or instances of transcendence, or grace.

19 The Problems of Resistance, 9

20 Theory \& Resistance in Education. 108

${ }^{21}$ In this section I will cite examples of dialogical intentionality, rather than dialogical reality, within monological systems. Sometimes "talk" cannot fully engage in dialogue due to one or the other party's lack of disclosure at the deeper level of encounter.

${ }^{22}$ Luther's resistance of conscience took place in a non-dialogical setting, principally due to the dominant religious system o his time, and partly also because of his own unbending convictions. He therefore resisted nondialogically within a dominant system.
} 
the end, criticism is only one side of resistance, a necessary but not sufficient guarantor of an ethical relationship.

Secondly, ethical resistance presumes a power-sensing rationality and a high-stakes course of action. In this sense it cannot be viewed as mere disagreement, which is not necessarily perceptive of power relations and can settle for a low stakes course of action. Consider this example: a change of administration in my school has brought about a new approach to supervising students whose teachers are away on school trips, for personal emergencies or for other extra-curricular activities that do not qualify for paid supply coverage. In order to reduce the number of "on-call" supervisions, ${ }^{23}$ students are pooled together in the cafeteria. This allows one on-call teacher to supervise two class groups at a time. The former method of assigning one teacher per class group and classroom absorbed too many on-call teachers at a time. This meant that by the month of May the contractual ceiling of X number of minutes per teacher for on-call assignments was already reached. Consequently, field trips had to be cancelled. However, the end value of favouring extra-curricular activities as integral to the students' high school learning and adolescent growth has overshadowed the value of in-school learning during these on-call sessions. Pooling classes together in the cafeteria has severely restricted the student's ability to do meaningful work and the teacher to exercise any pedagogical skills. Talking is allowed and the noise level becomes counter-productive to concentrating on seat-work assigned. The teacher's role has shifted from supervisory teaching resource person (in the former classroom on-call environment) to supervisory officer of a detention center-like space. From a power relations viewpoint, the students are held captive in an open environment by teacher-supervisors whose role is reduced to monitoring for deviant behaviour.

I have already expressed my disagreement with this administrative decision. It has been discussed at the Heads meeting. I have proposed alternative ways to ameliorate the learning environment to benefit students who are in school instead of on field trips. So far no corrective action has been taken. If I go to my next on-call supervision in the cafeteria, I have disagreed verbally and argumentatively without following through in my actions. I may accept this duty begrudgingly on the basis of having at least fulfilled my public duty to ensure the safety of students and to support the learning value of the students' extra-curricular life. Yet on the basis of my belief in ethical dialogue and the context of a safe, relational, trust-building environment for that to occur, I must call into question my disagreement with the current policy and practice that does not engage me in a total push against being co-opted "for a good cause." I can disagree by holding a different opinion from my administration and not act on it by a real commitment to a high stakes level of resistance, one that integrates my ethical position with my political will and my belief in dialogical learning with putting my energy into changing an expedient educational decision. The stakes will be raised when my resistance to this expected teacher-student arrangement combines argument with a refusal to supervise in that setting. The stakes will be raised when I have not only lost the argument, but perhaps my reputation as a cooperative staff member and supporter of extra-curricular activities. ${ }^{24}$ My own value of dialogical learning will be taken within the context of school power relations as a difference that divides and alienates. This will be the price to pay for authentic ethical resistance. Disagreement in most cases shies away from opposing dominant power structures. It does not matter that much, as long as one can express one's opinion. Ethical resistance takes a high stakes stand, one that may cost in terms of status and reputation, ${ }^{25}$ but which gives us the inner freedom to act consistently on the basis of one's conscience.

\footnotetext{
23 Supervision duties required by contract for a certain number of hours per term per teacher and are performed during a teacher's preparation time.

24 The assumption will be made that if I am not in favor of spending on-call time according to the cafeteria holding tank model, I must be against extra-curriculars and the teachers who promote them. This will become the political implication of my ethical resistance.

25 The complexity of power relations comes into the foreground as resistance in this context would collide with contractual settlements between the union and the board, extra-curricular-oriented colleagues, administrative
} 
Thirdly, ethical resistance can be expressed bodily or verbally, discursively or non-discursively. In this sense, resistance can be separated from the notion of dissent. Resistance and dissent have many points of contact between them. They are both tied to non-conforming, differing or oppositional responses. Yet the primary usage of the word dissent seems to be correlative to an overt, discursive difference of opinion or feeling. ${ }^{26}$ In the legal sense, it constitutes a position taken, articulated and defended against a majority view, such as among judges in a higher court. Resistance, though functioning similarly to dissent in terms of signifying difference from a common view, remains distinct as the underlying force of dissent. It correlates to covert realities such as the political "underground" and the psychological "subconscious." In the language of microbiology, it has to do with the defensive and adaptive capacity of organisms. The study of electricity associates resistance with "opposition" that generates heat. ${ }^{27}$ Giroux calls this the central category of "non-discursive behavior." 28 Resistance comes from experience that precedes the cognitive formulations tied to overt, discursive relations most often linked to dissent. It can be both rational and subrational, overt and covert in expression. It can include an "analytical construct and mode of inquiry," 29 but it also implies broader responses of emotion and belief that may not be readily captured through rational inquiry. What happens when dissent is suppressed by an oppressive force? The voice of dissent may be crushed, but the force of resistance persists. A Polish history professor of the University of Krakow continued to teach a dissenting version of history under the Nazi occupation, until the university was closed, thus stifling his voice of dissent. He decided to go underground, teaching classes in the basement of his apartment building, thus becoming a force of resistance with no public voice, yet generating a quiet, subversive impact. The non-discursive oppositional act of meeting clandestinely spoke of a conviction, a "capacity" and a "subconscious" force that remained undaunted in the face of silencing oppression. This professor was generating "heat" of a political and ethical kind that undermined oppressive power though voiceless and powerless at the level of dissent. ${ }^{30}$ As Martinot puts it, when protest is no longer heard and there is no room for public participation whether by means of dialogue, debate or dissent, resistance persists in "transgressing the boundaries of oppression." 31

To recapitulate, resistance as I define it confronts dominating people and systems as a total human response rather than as mere rational criticism. It refuses to be co-opted, unlike disagreeing with unethical policies while continuing to support them behaviorally. It implicates the resisting agent in a high-stakes engagement with political power. It persists in spite of silenced dissent as an expression of belief in humanity that transcends reason while at the same time sustaining oppositional action.

I have attempted to clarify my usage of ethical dialogue by contrasting it with discussion, debate, disagreement, and refutation. These processes of interaction do not always uncover inequities between parties. I believe ethical dialogue can only function when inequities are brought to light. Ethical resistance preserves one's own integrity as premised on conscience that animates the rational, acting being.

authority, students who don't value their own education, parents who react to hearsay in the community, etc. In this case ethical resistance cannot be dialogical with the individual on one side willing to dialogue while the authority structure on the other side chooses a monological response.

26 Dissent defined as "To differ in opinion or feeling; disagree." http://dictionary.reference.com/search?q $=$ dissent, Dictionary.com.

${ }^{27}$ See http://dictionary.reference.com/search?q=resistance, Dictionary.com.

28 Theory \& Resistance in Education, 108

29 Theory \& Resistance in Education, 110

30 I refer here to the historically-based novel Ces Enfants D'ailleurs by Arlette Cousture, Montreal: Libre Expression, 1992. In this instance, resistance did not lead to dissent nor to subversion. The intent of the professor was not to undermine or overthrow enemy rule in his country. Rather, his act of resistance, stemming from a decision of conscience regarding the value of educating, was judged to be subversive from the viewpoint of the Nazis. See "subvert" under Merriam-Webster Online \& "subvert" under www.Starware,com/ 2.0.0.0/landing/reference.

31 The Problems of Resistance, 9 
Resisting agency depends on being a person of worth regardless of one's political status or discursive ability.

Now that dialogue and resistance have been defined separately, how do they work together? How does dialogical resistance work as a dyadic tension? I will now attempt to unpack this notion as an essential ethical stance.

\section{Dialogical Resistance: The Linguistic Context}

In Burbules' etymological definition of dialogue we see the potential for resistance. He points out that prefix "dia-" suggests two, across, through, between and a spanning or connecting. The latter part, from "logos" refers to thought or judgment made visible through the connection. ${ }^{32}$ The fact of separation and the need to span it carries the dual seeds of difference and bridging, distance and connection, resistance and relation. In other words, closing the gap assumes there is work to be done in order to make the differences between people meaningful. It is only a matter of degree as to whether connecting involves simply verbalizing what two people already know to be the case, or in terms of a deeper divide, struggling to find a common starting point.

Martinot gives a political linguistic context for our second term of resistance. Resistance signifies crossing a border, usually of exclusion, to gain respect, to declare autonomy, to stake a claim among those who participate, to be heard. ${ }^{33}$ It basically consists of pressure applied against dehumanizing power in order to gain recognition and respect. Interestingly, resistance drives toward dialogue, exists for dialogical purposes. Its oppositional force ${ }^{34}$ serves to right dysfunctional ethical relations and create space for dialogue.

Certainly there are many levels and manifestations of dialogue and resistance, but fundamentally they are like two competing athletes inviting each other to the table. Dialogue inherently needs the presence of some degree of resistance and resistance makes dialogue operative. I outline some of the various degrees and manifestations of resistance in what follows, but I will define dialogical resistance here in the context of my teaching practice, as the pedagogical attitude and practice of inviting opposition to my dominant standpoint as teaching authority in the classroom. In other words, I will enable a process of decentering my dominant position and promoting interaction predicated on equal respect for all students as humans of inestimable worth.

I am not implying that the teacher must deny her own self-respect. She must stand her ground too, but not without allowing some of the unethical structural and interpersonal impact of her authority to be resisted by the students. The power of evaluation to control, limit, dominate, and silence students is one area the teacher must open up for discussion. The challenge for her will be to find the line of demarcation between respect and her role as evaluator. Therein lies the necessary work of dialogical resistance that I contend has not yet been sufficiently practised in our public classrooms.

A useful distinction can be made between dialogical and monological resistance. From the standpoint of a marginal person, monological resistance may fail to elicit dialogue with the dominant viewpoint, or may be applied indirectly and inefficiently, going inward or laterally, covertly or passively, like the boy who goes off to play basketball instead of showing up for a test. This is like pushing in on a barn door that only slides sideways. I did this as a student by resisting my college professor internally,

\footnotetext{
32 Dialogue in Teaching., 15

33 The Problems of Resistance, 9

${ }^{34}$ Henry Giroux builds in the factors of consciousness and analysis, two necessary conditions for dialogue as well: "...the concept of resistance (must) not be allowed to become a category indiscriminately hung over every expression of "oppositional behaviour." On the contrary, it must become an analytical construct and mode of inquiry that contains a moment of critique and a potential sensitivity to its own interest, i.e., an interest in radical consciousness-raising and collective critical action.” Theory \& Resistance in Education, 110.
} 
refusing to air my views for fear of provoking a dogmatic, repressive response. Conversely, in a classroom where the teacher's systemic power is challenged by the students' ability to distract, disrupt, and disavow the systemic agenda, a teacher may resist monologically by imposing added evaluation burdens as punitive power on the group, without negotiating dialogically through listening and reasoning. I used this option when faced with a group of well-connected immersion students who had been together as a homogeneous group since kindergarten. I reacted to their coordinated antics and subtle disruptions with the leverage of more frequent pen and paper testing. I learned nothing further about their motives and the concerns they were transferring into disorderly behaviour. I gained nothing more than more tests to mark.

I make a further distinction between dialogical resistance and "non-resistant" 35 dialogue. Technically, the latter is dialogue without tension, when one or the other interlocutor does not confront or engage. For example, a teacher takes on the guise of neutrality to manage a debate or a contentious issue among students. The intention may be not to impose one's views on the students. Unwittingly the teacher may be adopting a position of "false seduction into conformity" 36 to numbers, facts and surface knowledge, believing that only the skills and facts of the curriculum matter for evaluation purposes. By remaining "neutral" and "not biasing the argument with one's personal opinion" the teacher is by default complicit to a hegemonic evaluation system based on the "whats" of knowledge to the exclusion of "who," "why" and "according to what apparatuses and technologies?"

Is the only alternative to false neutrality teacher domination? Can a teacher resist students in the classroom without dominating? It is reasonable for the teacher concerned about the power he wields in the classroom to want to resist "imposing" his view or manipulating others. By playfully ${ }^{37}$, yet truthfully taking a different position from the students, the teacher may still promote the benefits of dialogical resistance. The teacher models positioning himself according to his background, values, religious convictions, etc. and thereby provides ample opportunity for students to take a different position while understanding his own more deeply. ${ }^{38}$ When the line of respect is crossed, 39 this dialogical confrontation of positions ceases to be ethical and the confrontation of views may have to be deferred. Unethical "dialogue" consists of asserting one's ego, refusing to disclose one's narrative self, siding unthinkingly with a group's position, name-calling, making prejudicial comments, etc.

On the side of the student, "non-resistant" dialogue may be evidenced by students who settle for cheap consensus, or who agree with two opposing standpoints at the same time, claiming they think both are "true." This unsituated or uncommitted relativism can in fact be a response to a deeper position of resistance. It may signal resistance to dialogue rather than resistance in dialogue, an opting out of being held to any position in particular. There may be viable reasons for this, such as the fear of being labelled by a certain influential person or group. But the upshot of this scenario is the loss of an opportunity for ethical development. If the influential group is known to the teacher, an alternative may be an interventionist move by which the dominant voice will be temporarily silenced for the sake of marginal views to be aired, or deconstructed to destabilize dominance. In an environment of sufficient mutual trust, students representing the dominant voice may allow their position to be challenged through attentiveness to the marginal view.

\footnotetext{
35 The quotation marks indicate the likelihood that non-resistance may be conceptually possible but in reality may conceal other related resistances lying behind this stance.

${ }^{36}$ Burbules, in Revolutionary Pedagogies, 256

${ }^{37}$ A pattern for meaningful dialogue that can be designed as a game, with agreed upon ground rules.

38 To resist playfully according to one's personal values requires a level of detachment from one's attachment to one's beliefs. This is not easily accomplished without a certain level of self-confidence that overrides defensiveness.

39 The teacher and students may agree in advance as to what constitutes crossing the line so that either the students or the teacher can be held to account.
} 


\section{The Philosophical Context}

What kind of educational philosophy will support ethical dialogue between teacher and students? The strength of dialogical resistance can be measured against certain traditional philosophies of education. I mention three here. 40

In the rationalist school a domination of reason over experience prevails, such as in the case of the Platonic justification for the "noble lie," ${ }_{11}$ an elitist program of seduction and manipulation of the masses for their own good and for the good of the state, a good only the elite can truly know. ${ }^{42}$ One manifestation of this type of school in our current context would glorify intellectualism and complex evaluation systems. Even within the public system, teachers can unwittingly create sophisticated rubrics of evaluation that students find difficult to understand. Second, in the naturalist camp, as represented by Rousseau, unfettered individual discovery becomes normative. Dialogue with the instructor does not seem essential, except to ensure the child understands the limits of safety for learning. The aim is to make a student's resistance to cultural hegemony a non-issue, since the natural learning environment precludes external acculturation. According to Rousseau, however, if the child oversteps the bounds of safety, taking unnecessary risks, the instructor must devise a hidden strategy to bring the child to his senses, as though the child were to have discovered it himself. ${ }^{43}$ Is this not a subtle form of manipulation, tantamount to monological resistance played out by both the student and the teacher? At what point does this covert game of resistances cross the line of "safety" over to psychological control? ${ }^{44}$ I wonder, for example, how many of my teaching strategies are methods of coopting students' interests to keep them in line with my own interests and objectives. Thirdly, we note a more flexible rationalism of the Deweyan stamp. This dialogical rationalism fits a democratic ideal within a monocultural North-American context. The parameters for dialogue, namely the means, language and symbols, are possessions of a dominant group of scientifically educated intellectuals. The process of dialogue follows the model of scientific research, where propositions are tested, verified and applied to new situations using cognitive processes of predictive reasoning. Though a certain plurality of views is understood in the claim that the truth is not given, but discovered and remade through a dialogical process, it is assumed the rational methodology must guide the educational inquiry. ${ }^{45} \mathrm{It}$ is the dominant modus operandi. I may easily misconstrue my students' resistance to evaluation schemes as resistance to learning, whereas in fact their motivation for inquiry may be muted by detailed and laborious expectations blocking their interest in learning. They may legitimately resist forms of the scientific method that precludes emotional intelligence, moral passion or divergent thinking patterns.

\footnotetext{
${ }^{40} \mathrm{My}$ references to historical philosophers in this part of the discussion are not intended as substantive critiques, as this would take us beyond the focus of my thesis. I refer to them more as types of pedagogical approaches here, to be contrasted with dialogical resistance. See my paper "Nature and Deception: A Comparative Study of Plato's Manufactured Myth and Rousseau's Invisible Fence" (2004) and "Dewey's Authoritarian Resistance to Fixed Educational Ends" (2004) for a more in-depth analysis of each author's views.

${ }^{41}$ Plato's Republic, Book V

42 Walkerdine echoes this rationalist ploy in making the claim that middle-class nurturance of preschoolers is a covert regulating practice for rational autonomy and mollifying conflict, a male gender-oriented rationalism that falsely assimilates the power of gendered desires, for example. Language, Gender and Childhood, 203-219.

${ }^{43}$ Rousseau's Emile, Book II, in particular the passage on the "whimsical child."

${ }^{44}$ In Rousseau's own words: "Are not his (the student's) games, his pleasures, his pains, all in your hands without his knowing it? Doubtless he ought to do only what he wants; but he ought to want only what you want him to do. He ought not to make a step without your having foreseen it; he ought not to open his mouth without your knowing what he is going to say [italics mine]." Emile, 120

45 Dewey holds to the scientific method whereby education consists of "a plan and method of action based upon foresight of the consequences of acting under given observed conditions...." Experience and Education, 69
} 


\section{Corroboration of Current Authors}

The dyadic tension of dialogical resistance accommodates some current research on dialogue within shifting power relations. The basic claim is that dialogue cannot be enacted in a power vacuum in any real way. Exchanges between real persons in actual situations do not happen like butterflies lighting on blades of grass. When we ask who initiates dialogue, how it is done, where and on what terms, resistance seems inevitable. There is a splash effect, more like a rock thrown on the surface of the water. Also it is important to note that resistance in dialogue happens at various levels of intensity. It can range from non-participation in the "acceptable channels," 46 to straining for clarity through intense questioning, to refusing to comply with demands, to risking one's life in order to change the balance of power. Burbules recognizes that dialogue may not always be possible, due to fluid, shifting differences that thicken the layers of resistance in imbalanced power relations. ${ }^{47}$

There can be so much resistance from various voices of difference that dialogue breaks down. There can also be so little resistance allowed for by the voice of dominance that dialogue is no longer safe. When my administration group listened in silence to my presentation on "non-compliance" in a session originally designed for their professional development agenda, ${ }^{48} \mathrm{I}$ had no assurance that they really listened, willing to make any changes to current practice. Would my critical view that "noncompliance" is a term designed to sustain the dominant group's comfortability be used against me? Would non-compliant behaviours be heeded or ignored as a result of my presentation? In this case, my opportunity to resist the misnomer of "non-compliance" tied to imbalanced power relations was tolerated but not necessarily deemed important enough to provoke change. As Jones points out, giving voice to a marginal standpoint does not change the dominant position and may put the marginal view at further risk. ${ }^{49}$ Where trust cannot be presumed, giving voice to marginality may in fact be a form of voyeurism on the part of the dominant group, a calculated act of getting a glimpse of the inner workings of a resistant mind in order to better control it. Where a dominant position does not make itself vulnerable to resistance, dialogue can only be perfunctory. When speech is regulated in terms of vocabulary usage, time constraints, or physical context, the "crossing over" requirement of dialogue remains incomplete. ${ }^{50}$

Dialogue can be likened to two people of equal weight (in terms of worth) facing each other on a sailboard. When one moves, the other must shift positions in order to maintain the stability of the board. There is power (motion) and resistance (counter-motion) in equal measure. My presentation to my colleagues in the presence of the administration group was more like trying to climb up into someone else's yacht from the water line. Climbing up the side may be difficult, and one's reception depends on the disposition of the owner. Will the owner speak my language? Will he view my "visit" as an intrusion or an opportunity to listen to my story? Regardless, the position of the yacht itself will remain unchanged by my coming aboard. Mayo states that when the voice of resistance is taken as a mere opinion, it does not pose a "threat of substantial disruption." 51 The imbalance of power stays unperturbed and the ship sails on.

46 Burbules refers to acceptable channels as limitations to open dialogue. Clearly, who sets the linguistic, geographical and technological terms for dialogue will have the advantage at the outset over those who have limited access to these tools of dominance. See Revolutionary Pedagogies, 251.

47 In Trifonas "The Limits of Dialogue as a Critical Pedagogy," 251-273

48 See my paper "My Non-Narrative Teaching Persona."

49 This is why "silence may be a rational response to their (dominant) peers' lack of ability to hear and understand." ; see Jones' chapter "Talking Cure: The Desire for Dialogue," in Boler, Democratic Dialogue in Education, 60

50 In the case of my presentation to my colleagues and administration as another paper, the vocabulary of "compliance" was idealized, the time constraints were imposed by the administration, the physical context was a room not large enough to break out into smaller discussion groups.

51 In Boler, Democratic Dialogue in Education,, "The Tolerance That Dare Not Speak Its Name" , 39 
$\mathrm{Li}$ shows us that even the resisting potential of silence can be lost to systemic practices of hegemony. Instead of silence being an option within the dialogical process as a means for critical thinking or mounting an expression of difference, it has been co-opted into regimented forms of deriving predictable spoon-fed answers. She writes: “...the current accountability movement is so outcome driven that many teachers are inclined to view silence as a mechanical device for soliciting observable and measurable responses in either verbal or written form." 52

This dictated surface silence may in fact raise the internal decibel level so high that a deeper, ponderous, questioning silence is reduced to a deadening inner silence, where resistance gives way to the constant noise of the "right answer." This makes for a pedagogy of informational belligerence. The teacher demands, waits for, expects and extricates predetermined bits of information from the students. I observed this pedagogical style in a grade six classroom where the math teacher kept his questioning on simple math problems so fast-paced, interrogating one student after the other in quick succession, that silence would be counted as "not knowing the answer," subjecting the "silent" student to repeated rounds of questioning until the right answer was pronounced. Silence from the standpoint of the students was a source of angst, of being "dumb," and from the position of the teacher, a monological mechanism of control. Those who intentionally remained silent as an act of resistance remained outside of any dialogical process. Their performance was simply evaluated as "falling behind."

Dialogical resistance incorporates silence as an open-ended, sometimes conflictual response to dominance that invites criticism, correction, and confrontation for the sake of ethical pedagogy. As I learn to listen to the silences of my students in this light I can forge new, more inclusive directions with them. ${ }^{53}$

\section{The Anchor of Respect}

The possibility of integrating resistance with dialogue as a condition for authentic communication hinges on the attitude of respect. In what follows I link current authors' views to the ethical ground of dialogical resistance. In this regard I turn to Buber's work as a necessary piece of the philosophical context outlined here.

Glass makes this strong claim: "Respect for differences and for those who oppose the liberation of the oppressed can be maintained...even as we combat their positions and power..." 54 This is a tall order indeed! In my view it is unlikely that high school students would be inclined to respect teachers who oppress them unless respect has been modeled by other significant teachers in their lives and practised dialogically. Glass is referring no doubt to a more mature group of people, possible university graduates. In any case, respect cannot be assumed.

However, Buber resonates with Glass's ideal. He even imagines entering a dialogical process with Adolph Hitler, who was his contemporary. ${ }^{55} \mathrm{He}$ is able to at least imagine the possibility because of his deep belief in humanity. In terms of teaching younger students, he places the weight of responsibility for cultivating respect on the shoulders of the teacher. He portrays the teacher's respect for students as

\footnotetext{
52 Democratic Dialogue in Education, "Rethinking Silencing Silences," 73

53 As a student at l'Université de Montréal, my silence as one who was not able to identify with the subjective approach to pedagogy was misinterpreted by one of my professors as "drug use." A monological assumption had been made that prejudged my lack of involvement as social deviance. How many prejudicial views do we take as teachers toward students due to cultural, linguistic, racial, class or even learning style differences?

${ }^{54}$ In Boler, Democratic Dialogue in Education, "Moral and Political Clarity and Education as a Practice of Freedom," 26

55 Buber calls this situation "dialogical powerlessness" due to his judgment that Hitler would be "incapable of ...really listening." Nevertheless Buber does not back away from engaging dialogically with antagonistic "partners" in dialogue. See Schilpp, The Philosophy of Martin Buber, 725
} 
the bedrock material for dialogical relations that cannot be seduced into patterns of domination and subjection. He likens the pedagogical relationship to that of a doctor and patient:

It is essential that this should be a real human relation experienced with the spirit by the one who is addressed; but as soon as the helper is touched by the desire -in however subtle a form- to dominate or to enjoy his patient, or to treat the latter's wish to be dominated or enjoyed by him other than as a wrong condition needing to be cured, the danger of falsification arises. ${ }^{56}$

The strength of Buber's position here is that his refusal to dominate signifies a respect that is not skin deep, or in pedagogical terms, behaviourally conditioned. It takes into account the power relations that condition even the "wish to be dominated" and resists them out of respect for the person's worth qua person. ${ }^{57}$ The teacher who passionately holds to respecting students regardless of their level of resistance to dominance has sufficient intra-personal, interpersonal and systemic knowledge to consistently step away from opportunities to dominate. ${ }^{58}$ Due to the "terrible asymmetries and inequalities of power" 59 endemic to teaching, it is incumbent on the ethically-minded teacher to speak critically to his own "current resistances, conflicts, confusions and tensions" 60 in order to struggle for dialogical equilibrium where respect prevails over access to power. When a student chooses not to resist but to incite a "power over" relation in the teacher, Buber believes a teacher must resist for and in spite of the student, as a means of striving for an ethical culture of dialogical resistance.

The basic principle of respect applies to evaluation practices, for example. I must struggle with the uses and abuses of control in testing whether or not my students resist. In fact, they are so conditioned to be passively receptive to testing that unless I openly begin to critically examine the content and procedures of tests, my students will not learn to become critically aware of the issues themselves.

\section{The Complexity of Resistance}

Overt political resistance is an extension of developmental psychological resistance. Resistance per se is intrinsic to humanness. ${ }^{61} \mathrm{In}$ my vision for education I see resistance as integrated in healthy relational patterns ${ }^{62}$ and becoming a constructive pattern for enhancing a living democracy, as an alternative to repression and violence.

We cannot overlook the fact that political and structural conditions intertwine with developmental resistance early on. The mother's responses to a child's attempts at autonomy, part of which involves resisting the mother's proximity, wishes, instructions, etc., are themselves inscribed in familial, cultural and political structures. These contribute to the formation of covert and overt resistances in the child's psyche that will persist into adult public life. Through parental modeling and

\footnotetext{
56 Between Man and Man, 123

57 In Applebaum's words, recognition respect consists of "looking again" or more deeply to appreciate the human dignity of those who we may disagree with. This is respect by virtue of inherent worth. The other type of respect - earned respect has more to do with judgments and evaluations made based on performance, the standards for which vary depending on the situation. In Philosophy of Education, 1996, 81

${ }^{58}$ I unpack these three areas of consciousness in my paper "Three Pedagogical Levels of Dialogical Resistance".

${ }^{59}$ Burbules on Garrison in Boler, Democratic Dialogue in Education, xix

${ }^{60}$ Burbules on Houston in Boler, ibid, xix

${ }^{61}$ See my review of Buber's account in my paper "Dialogical Resistance and Buber".

${ }^{62}$ Resistance as an oppositional force is not denied by this statement. My claim is that it can be an expected, if not always desired, part of ethical relations.
} 
training the child learns to resist either confrontationally or indirectly, strategically or impulsively, within given norms or autonomously, to name a few patterns.

Two aspects of the parent-child relationship ${ }^{63}$ lay the foundation for dialogical resistance: selfrespect and self-disclosure. Basic self-respect develops when psychological resistance to the maternal bond gives way to the need for autonomy. Buber calls the end of this developmental process "deep conscience," the power to stand on one's own position, take into account other standpoints, and oppose heteronomic pressures that require capitulation of the individual will. ${ }^{64}$ In other words, selfrespect means recognizing the difference between negotiating shifting power relations and subjugation. One may be willing to negotiate, but not to subjugate one's own will to dominance. In this way resistance and self-respect work together in identity formation.

Self-disclosure, on the other hand, stems from what Buber calls the primal "longing for relation," 65 the first motivation for dialogue. He calls this dialogic impulse "presencing," signifying wholly and openly connecting one's narrative self with others. Our basic human need for self-disclosure lays the groundwork for dialogue, in terms of a reciprocal unveiling of positions.

Therefore resistance originates in self-respect as the boundary for dialogue, the basic motivation behind oppositional, defensive and offensive forces that protect personal autonomy. On the other hand, dialogue originates in longing for connection, the precursor to mutual disclosure of values, positions, self-narratives. By nurturing and testing the dyadic tension of dialogical resistance in the intimate bonds of the home and school, the potential for building trust and honest relations in the public arena increases. Obviously, the manifestations of these basic attitudes become complex as children move into adult life and engage in a diverse web of contradictory power relations. Marginal groups may resist monologically, overtly or covertly depending on their particular learned patterns of relating and on the situational contexts they encounter. Some will resist based on a direct appeal to individual conscience, others will yield to group pressure, some will resist merely to survive, others to advance, still others will become more self-aware while failing to be cognizant of interpersonal and systemic power relations.

Although Buber's foundation for dialogical resistance has merit, he does not account for some of the complexities of power relations. The hidden structures of political and social life may become so multilayered that resistance only contributes to dialogue in ambiguous ways. Although in principle overt resistance will be more conducive to authentic dialogue than covert resistance, there are many contingencies. Overt resistance may not be received by the dominant players, in which case resistance may provoke more domination than real dialogue. The success of overt resistance will be contingent on two basic premises: first, that self-respect has not been damaged to the point where conscience cannot speak, and second, that self-disclosure has not been closed down due to violations of presencing oneself in the face of dominating agents. A marginal person or group who has sufficient systemic and interpersonal awareness may nevertheless choose to resist covertly and count the losses.

Consider the illustration of a difficult examination question. A student writing the exam does not understand the question. She thinks it is unclear and poorly stated. What are her options? By asserting the question is not clear, will she be transgressing the authority of the teacher? Will raising the question audibly transgress a rule of silence during examinations? Will the teacher be helpful or evasive, patient or defensive? Will the question be perceived as intelligent or insolent? Will self-disclosure of confusion or critical questioning bring embarrassment or relief? Does she have adequate self-respect to persist? The answers to these questions bring a range of power relations into play: the student's upbringing and

\footnotetext{
${ }^{63}$ Buber understands this parent-child relationship within the Judeo-Christian, Eurocentric perspective, where there is a gradual weaning process from physical and emotional bonding with the mother to individuation as the child becomes more self-conscious.

${ }^{64}$ Buber defines conscience as "the capacity and inclination of men to differentiate radically between what they can assent to or dissent from within their past and future attitudes." The Philosophy of Martin Buber, 568

${ }^{65} \mathrm{I}$ and Thou, 77
} 
internal "dialogue" of self-respect, her cultural background, the teacher's interpersonal skills, the systemic practice of "final" examinations, the student's social position in terms of reputation in the school culture, etc.

The student could take a different course of action by simply writing an answer to the question according to what she guesses it to mean, or by writing "I don't understand this question" as her answer. She may very well feel that confronting the teacher and the systemic culture of examinations will be too costly in emotional energy and the struggle to change dominant perceptions. In this case a more covert act of resistance -a written statement- bypasses the direct route of dialogical resistance. The student does not seek further clarification or interaction with the supervising teacher.

There are other possible manifestations of student resistance, but in the end the regulatory practice of examinations diminishes access to dialogical resistance. The fact, format and function of final examinations buries the effectiveness of resistance under the weight of time constraints, the finality of the evaluation, the pressure to obtain good grades, the tacit belief that students "ought to know the answer by now", parental pressure, promotional needs, administrative data collection for school ratings, etc.

The complexity of the issues to be confronted may escape the student's consciousness, selfrespect may be damaged, self-disclosure silenced and therefore the energy required to keep up the intensity, duration and scope of resistance necessary to confront the dominance of the regulatory and systemic practice may be too daunting.

\section{Dialogical Resistance and Asymmetry}

It is difficult to imagine a pedagogy of hope along the lines of dialogical resistance as a precursor to participatory democracy unless there is a shared commitment from both teacher and students. What if the teacher, who holds most of the power, is ego assertive, takes a self-concealing, non-narrative personal stance, and typically silences any form of resistance? In this situation, the students could engage in monological resistance -a recipe for subversion in the absence of true dialogue or "nonresistant" dialogue- a most superficial way of "getting along" in order to avoid further repression.

In my view dialogical resistance that accounts for asymmetry and remains productive as a means for ethical growth depends on the teacher's willingness to be self-critically aware, interpersonally receptive to resistance within the bounds of respect, and prepared to resist systemic pressures that inhibit open and honest dialogue in the classroom. Three levels of critical consciousness ${ }^{66}$ and their implications will be further explained in Chapter Four. I highlight them here to demonstrate how dialogical resistance can take asymmetry into account flexibly and usefully.

First, a teacher hoping to encourage dialogical resistance should be intrapersonally aware enough to separate passion for dialogue from ego assertion. Within the oscillating motion of connecting and resisting, talking and thinking, engaging and withdrawing, space needs to be provided for the simultaneous activities of interpersonal dialogue -talking, and intrapersonal dialogue- journaling, reflecting, thinking; of confrontational dialogue and meditative silence. Unless the teacher manifests an inner passion for this kind of dyadic oscillation, ${ }^{67}$ dialogue may soon be felt by students as mere ego assertion. This unethical assertiveness can be felt where the teacher's rule "thou shalt dialogue!" becomes a "power over" stance leading to false dialogue among the "deaf." This is why both interpersonal and intrapersonal attentiveness must be working together. Without critical self-awareness, dialogical resistance can degenerate into a battle of wills or a cacophony of superficial points of view.

\footnotetext{
${ }^{66}$ Intrapersonal, Interpersonal and Systemic levels.

${ }^{67}$ I call this also "Unethical Swings of the Pendulum", between non-resistant dialogue, at one end of the pendulum, and non-dialogical domination at the other end. In Buber's language, the pendulum swings between the I-Its of abstraction and absorption.
} 
The fact of asymmetry requires a second level of questioning. What are the possible impacts of a self-narrating teacher? The dialogical usefulness of sharing narratively from one's personal journey may at times be taken by students as natural self-disclosure, but it may also be construed as imposing one's values or "personal life" on them. What are the considerations for approaching dialogical resistance through self-narrative? The mode of communication may be varied, from oral to written to pictorial to "third person" story-telling. Also, the context needs to be ascertained. If the self-narrating teacher expresses a marginal point of view, we must ask, "Is this a context for controversy, where students are ready for a different point of view, or will shifting power relations mitigate trust through controversial dialogue?" A group's tolerance for resistance varies according to levels of trust, respect, and practice. Also, what is the intent? Is it to provoke a written response, an emotion, a starting point for student narrative extensions, or is it to promote ostentatiously the teacher's own values and beliefs? These are some considerations for assessing an ethical approach to a teacher's self-narrative in asymmetry.

Thirdly, at the interpersonal level there is a distinction to be made between a teacher's silence that speaks ethically and silence that closes ethical space. The teacher may resist verbal engagement with a student by dialoguing non-verbally, through gesture, mime, facial expression or a smile. This may be instrumental for learning as creative wait time, where subtle clues are given to provoke reflection, deeper thinking, or just a guided response. By contrast, unethical silence manifests itself as nondialogical positioning, aloofness, physical distance and a monological paucity of words. This may have the effect of increased control over the students, who are forced to guess or ignore the pedagogical direction being taken, or it may be a form of resistance to being controlled by the students, as a sort of counter-resistance.

Fourthly, dialogical resistance must allow personal consciences to speak, as both connective and disconnective. This may be the acid test of the level of respect between teacher and students. When a student or the teacher shares at this level, the risk touches both the core of their self-respect -abiding by one's conscience -and of their freedom of self-disclosure- trust leading to fully presencing oneself before others. The connective power happens when there is appreciation for the deeper part of the individual's psyche. But it can be disconnective when conviction and emotion associated with expressing one's conscience impact others as dogmatic, inflexible, or intolerant. The teacher's role will be to counter the disconnectivity of conscience -where it is expressed in a harsh or volatile manner, for instance- by drawing out the human depth elements of conscience, to tactfully show similarities in intensity, thoughtfulness, and shared values, perhaps expressed in different ways. For example, one can reason that those who oppose capital punishment as a matter of conscience and those who uphold it may both hold to the supreme value of life worked out toward opposite conclusions. This common value needs to be pointed out as a connecting rod between opposites. In terms of the end judgment, an emphasis needs to be placed on understanding rather than agreeing. Different strategies can be used to maintain dialogical resistance that does not degenerate into a battle of emotional resistances and counter-resistances, or an assertive diatribe of one voice of conscience against another. ${ }^{68}$

Fifthly, at the level of systemic consciousness the teacher needs to know that at times the intent to be inclusive may have the unexpected impact of exclusion. To illustrate, let me refer to my grade ten immersion curriculum. I use a French Canadian short story to illustrate the importance of respecting other people's physical appearance. The theme was a young boy's perspective on the cruel comments some pubescent girls received from their teacher regarding their appearance, in this case a Catholic nun. I use this story as hyperbole in order to make a case for respecting the appearance of those who are different from us, who may be self-conscious about it and who have not chosen the way they look, etc.

Following one lesson two girls approached me and expressed their discomfort in being indoctrinated in the Catholic religion. I had used a literary context to illustrate the importance of

\footnotetext{
${ }^{68}$ Strategies that defuse visceral wars may include mapping philosophical starting points and their implications, interviewing opposite views instead of immediate open debate, inviting guest advocates to expand on opposite convictions, a journal of feelings, an invitation to research the opposite viewpoint and so on.
} 
inclusion, and they interpreted the context as exclusionary of their personal beliefs. What I had not anticipated was the systemic power of coercive inclusion these girls sensed through this piece of the curriculum and the power relations that encompassed it. Their sense of being excluded, or more precisely coercively included, was due to a number of systemic apparatuses. I list a few of them. First, a male teacher had selected the story and attempted to make it inclusive of female students. Depending on their experience with adult males, ambient gender issues may have played a significant role in their response to the text. Secondly, the religion portrayed was mandatory in the context of the school described in the story, just as this piece of literature was mandatory in the course. My lesson on "inclusion" could then be felt as coercive. Thirdly, the story was about dominating female students' self-concepts, a pressure these two female students had transferred from the language of sexual identity to their feelings about religious language and symbols. They made a connection between the repressive religious context described anecdotally and the threat to their sense of identity as females. In the end, my attempts to teach inclusive attitudes seemed to have had the impact of downward inclusion. ${ }^{69}$ Perhaps a less didactic, compulsory and focused approach could have helped curb my students' suspicion of somehow being included against their will. I needed to be more conscious of the impact of the ideological, gendered and pedagogical power relations.

Lastly, the ethical teacher will choose to resist a system that pressures students to compete against it. This message could be no clearer than in the area of evaluation by grades. Students learn quickly to try to beat the system by negotiating, manipulating, calculating, and cheating in order to get the "number" they want. Changing the numbers to less threatening benchmarks such as colour codes, peer evaluation, anecdotal comments, or progress reports may appear to be more cooperative, more conducive to "competing together," but they are more often than not subtle forms of co-opting student performance into a monolithic ranking system. If, in the interest of taking the pressure off performing for marks, the teacher states the task is not going to register in the reporting cycle, the students react by not taking it seriously. If colour codes for levels of participation are recorded, the students will demand to $\mathrm{know}^{70}$ their numerical value. Within the asymmetrical relationship, the teacher is most often viewed as the evaluator and judge according to a scale of quantifiable symbols. ${ }^{71}$ The challenge will be to resist hierarchical nomenclature by finding ways to balance it against a more cooperative relationship -as co-investigators, co-learners, or in Buber's words as "pointing the way"-and a more meaningful end- fulfilling one's passion for learning.

\section{Summary}

In review, from the etymology of dialogue and resistance I have made linguistic and philosophical connections and distinctions that lead to a dyadic tension that oscillates on a sliding scale of intensities, consciousness and contexts. It fluctuates between critique and affirmation, passivity and activity, formation and confrontation, openness and hiddenness, the personal and the systemic, anticipated and unexpected. I have suggested through several examples how dialogical resistance serves as pedagogy of hope as it works to decenter dominance and safely engage students. I have referred to Buber's consistent passion for the anchoring role of respect. Further exploration of this core value of respect

\footnotetext{
${ }^{69}$ Here I stress impact rather than intent, as there was sufficient trust to discuss the issue and make some adjustments to my pedagogy.

70 This has been my experience in the secondary school system in Ontario, at least.

${ }^{71}$ Students often rate teachers according to who gives out higher grades. They may choose classes based on which teacher is an "easy marker" or a "hard marker." In this sense numbers matter more than anecdotal comments, an approach to teaching, communication skills, or other assessment devices.
} 
will be required to assess how Buber's view might hold in the face of the complexity of situated positions, dominance, and repression.

\section{References}

Applebaum, Barbara. 'But That is Not What I Mean' - Criticizing with Care and Respect in Philosophy of Education. Urbana: Philosophy of Education Society. 1996.

.'On Good Authority or is Feminist Authority an Oxymoron?' In Philosophy of Education. 307-319. Urbana: Philosophy of Education Society. 1999.

Boler, Megan. Feeling Power. NY: Routledge. 1999. - ed. Democratic Dialogue in Education -Troubling Speech, Disturbing Silence. Peter Lang: NY. 2004.

Buber, Martin. Between Man and Man. NY: Collins. 1947.

. Pointing the Way -Collected Essays. M. Friedman, ed., transl. London: Routledge and Kegan Paul. 1957.

The Way of Response. N.N. Glatzer, ed. NY: Shocken. 1966.

I and Thou. NY: Simon \& Schuster. 1970.

. The Knowledge of Man -Selected Essays. M. Freidman, ed. Amherst: Humanity Books. 1998.

Burbules, Nicholas C. and Rice, Suzanne. 'Dialogue Across Differences : Continuing Conversation' in Harvard Educational Review. Nov. 1991; 61, 4; Wilson Education Abstracts. p. 393.

Dewey, John. Experience and Education. NY: Simon and Schuster. 1938. . Democracy and Education - An Introduction to the Philosophy of Education. NY: The Free Press. 1944.

Friedman, Maurice S. Martin Buber-The Life of Dialogue. NY: Harper \& Row. 1960. 'The Bases of Buber's Ethics' in The Philosopby of Martin Buber. Schilpp, Paul A.Ed. Lasalle, Illinois: Open Court. 1967. 171-200.

. 'Martin Buber and Emmanuel Levinas: An ethical query' in Pbilosophy Today. Celina: Spring 2001. Vol. 45, Iss. 1; pg. 3, 9 http://proquest.umi.com.myaccess.library.utoronto.ca/pqdlink?index $=15 \& \mathrm{did}=71529767 \&$ SrchMode $=1 \&$ sid $=2 \& \mathrm{Fmt}=3 \&$ VInst $=$ PROD $\&$ VType $=$ PQD $\&$ RQT $=$ $309 \&$ VName $=$ PQD $\&$ TS $=1115224118 \&$ clientId $=12520$

Giroux, Henry A. Theory \& Resistance in Education: A Pedagogy for the Opposition. Massachusetts: Bergin \& Garvey Publishers, 1983.

Macmurray, J. Persons in Relation. NY: Harper. 1961.

Martinot, Steve; James, Joy. The Problems of Resistance -Studies in Alternate Political Cultures ed.. NY: Humanity Books. 2001.

Niebuhr, R. Moral Man and Immoral Society. NY: Scribners. 1932.

Noddings, N. 'Two Concepts of Caring' in Philosophy of Education. NY: Columbia University Teacher's College. 1992.

. The Challenge to Care in Schools. NY: Teachers College Press. 1992.

. Educating Moral People - A Caring Alternative to Character Education. NY: Teachers College Press. 2002.

Plato. The Republic. trans. Francis MacDonald Cornford, London: Oxford U Press. 1945. . Protagoras and Meno. trans. W.K.C. Guthrie, London: Penguin. 1956.

Rousseau, Jean-Jacques. Emile or On Education. trans. Allan Bloom, Basic Books. 1979.

Schilpp . Paul Arthur; Friedman, Maurice, eds. The Philosophy of Martin Buber. London: Cambridge University Press, 1967.

Trifonas, P.P. ed. Revolutionary Pedagogies : Cultural Politics, Instituting Education, and the Discourse of Theory. NY: Routledge Falmer. 2000. 


\section{About the Author}

Rob Foster has been teaching for 20 years in secondary education in Ontario. He has co-authored Ministry of Ontario curriculum profiles for French as a Second Language, and has a particular interest in evaluation and assessment. He lives in Port Perry, Ontario, with his wife Bev and four children. 